\title{
Heurestika Dalam Hal Pendidikan Karakter Kristen Yang Supralogika Terhadap Budaya Toraja
}

\author{
Gita Pala'langan \\ Lembaga: IAKN Toraja, posel: \\ gpala2988@gmail.com
}

\begin{abstract}
In the study of the topic there are several reflections that will be our research in education science through culture or logic in traditional Toraja culture which aims to show how to respond to the education that we still lack.
\end{abstract}

Abstrak : Dalam kajian topik ada beberapa refleksi yang akan menjadi penelitian kita dalam ilmu pendidikan melalui budaya atau logika dalam budaya toraja tradisional yang bertujuan untuk menujukkan bagaimana hal menyikapi pendidikan yang masih kurang yang kita miliki. Kata kunci: Heuristika, Pendidikan Kristen, Supralogika, Budaya 


\section{Pendahuluan}

\section{A. Latar Belakang}

Dalam pendidikian kita harus membutukan sikap dan karakter dalam pendidikan yang betul-betul untuk menguasai diri kita sebaliknya juga menguasai ilmu-ilmu dalam pendidikan itu. Penelitian ini adalah penggabaran kebijaksanaan orang toraja dalam budaya tradisional, yang menunjukan bagaimana mereka merawat atau melestarikan supra logikanya untuk pertumbuhan kulitas hidup meraka denagn membudidayakan kultur sebagai medium heuristika. Topik diatas kita akan membahas tentang tujuan dan manfaat-Nya terutama dalam hal merefleksikan dalam kehidupan pendidikan kita.

\section{B. Tujuan dan Manfaat}

Dalam hal heurestika mengenai pendidikan yang beraktualisasi supralogika orang toraja tradisional bertujuan untuk orang-orang yang berpendidikan juga kita yang masih dalam proses menuju ke masa depan yang mempunyai logika dan untuk manusia yakni dalam budaya toraja yang pendidikan masih kekurangan pemikiran atau masih tidak baku dalam hal menanggapi suatu permasalahan dan perjalanan hidup yang menajadi suatu tantangan dalam menjalani aktifitas sebagai seorang pendidik, terutama dalam perguruantinggi.

Mafaatnya adalah seorang pendidikan Kristen bagi anak dalam keluarga dan pembelajaran agama di sekolah biasa dijadikan suatu pandangan kebaikan dan umum dalam berjuang pendidikan memungkinkan seorang bertindak bijak hidup serasi dalam komunikasi dalam hal ini juga kita biasa mengepresikan kehidupan kita untuk menjadi seorang yang berpendidikan untuk membawa kehidupan kita ke masa depan yang lebih baik dan menunjukkan bahwa masa depan yang kita punya bisa dikembangkan melalui pemikiran dan logika. 


\section{Pembahasan}

Di dalam pendidikan ini untuk menunjukan bahwa pendidikan bukan sekedar institusi pendidikan belakang atau tidak hanya sekedar latihan intelektual saja tetapi juga membutuhkan upaya heuristic yang baik. Pendidikan belum pantas disebut pendidikan apabila mengabaikan pembentukan karakter. Budaya mereka.budaya mereka merupakan hasil olah rasa dan karsa menjadi daya Tarik bagi berbagai phak dari luar entah untuk diteliti maupun dalam tujuan publikasi dan dokumentasi. Kehidupan dan budaya orang Toraja tersebut menggambarkan kualitas berfikir dan kualitas hidup mereka. ${ }^{1}$

Dalam hal ini hendak menguraikan gandamer dalam empat konsep yakni bidang kebudayaan, sesnsus communis atau suara hati atau kalbu, pertimbang taste atau selera. Khalayak dalam kebiasaan berbahasa, acapkali mengalami kacanduan dalam membedakan insting dan intuisi termasuk dalam pengambilan keputusan. ${ }^{2}$ Dalam kajian gagasan sensus communis - lah yang memungkinkan seorang bertindak dan mempunyai karakter yang baik dalam mengyikapi suatu pendidikan. Dalam hal ini tuhan akan menggunakan hubungan dan contoh keluarga dan komunitas Kristen untuk mengomunikasikan isi dan subtansi iman kepada anak-anak dan dia akan meragenerasikan dan kemudian membawa merekah kepada iman melalui proses socialization. Namun pertanyaan sentral dalam pendidikan Kristen adalah bagaimana cara terbaik kita mengajarkan iman dengan logika. Melalui pendekatan sebagai supralogi adalah keterbukaan terhadap yang lain, apapun bentuknya baik teks, bunyi musik, atau pun karya seni, yang kebenarannya tadapat dicapai dengan metode ilmiah.

Kajian ini diharapkan memberikan manfaat bagi pelaku budaya dan pemerhatian pendidikan. Kesimpulan setelah menganalisis hasil temua dan menyimak data serta informasi. Kebudayaan dalam masyarakat berfokus pada riset dalam kajian kearifan local. Yang dapat ditarik dari penelitian ini, teryata stratifikasi sosial masih memiliki pengaruh sosial sangat kuat dalam budaya toraja barat ma'pasilaga tedong dan ma'pasisaung manuk. Kondisi factor ini Nampak secara nyata dalam hal struktur adat budaya toraja dan menambahkan sebagian yang tidak baik di mata orang beragama atau pun sebagian masiyarakat toraja dengan menggunakan judi. Walaupun toraja masyarakat menyadari bahwa perbuatan judi tidak baik ( ma'pasilaga

\footnotetext{
${ }^{1}$ Rannu Sanderan, "Heuristika Dalam Pendidikan Karakter Manusia Toraja Tradisional," BIA': Jurnal Teologi dan Pendidikan Kristen Kontekstual 3, no. 2 (2020): 306-327.

2 Rannu Sanderan, "Pendalaman Gagasan Hans-George Gadamer Tentang Intuisi Sebagai Supralogika," jurnal IImiah Relogiosity Ettiy Humanity(JIREH) VOL.2 (2020).
} 
tedong dan ma'pasisaung manuk. ${ }^{3}$ Hal ini sebenarnya tidak ada di dalam alkitabiah, namum juga sebagian masiyarakat toraja melakukannya. Namum seiringan dengan waktu yang berlalu masyarakat toraja sudah menganggap biyasa di dalam lingkuan masyarakat toraja. Dan sekarang mulai juga anak dewasa mulai mengikuti perilaku itu karna melihat dari perilaku atau perbuata orang terdekatnya sehingga mengikut dan melakukan ( perjudian ) baik di ma'pasilaga tedong, ma'pasisaung manuk, dan juga lainnya. Disitulah anak-anak sekarang tidak takut atau tidak tau apakah judi itu dosa atau bukan melakukan walapun banyak orang yang melihat, dan sampai sekarang mereka tetap melakukannya di karnakan sudah terbisayasa melakukan atau melihat orang terdekatnya. Bisah dikatakan dilingkungan itu sudah terbiyasa.

Ada beberapa cara untuk menghilakan kebiyasaan melakukan perjuadian di masyarakat toraja dengan melakukan, pendidikan karakter merupakan proses panjang sebagaimana sebuah usaha untuk mendidik anak agar memiliki pengetahuan, dapat merasakan dan mempraktekkan nilai-nilai ( vlues ) kebijakan ( vitues ) dalam kehidupan sehari-hari, sehingga memberikan dampak positif kepada lingkunan sekitarnya. Untuk menghasilkan karakter baik memiliki tiga unsur/komponen pokok, yaitu mengetahui kebaikan (knowing the good), mencintai kebaikan (desiring the good), dan melakukan kebaikan (doing the good), maka orang berkarakter diartikan sebagai sifat alami seseorang dalam merespon situwasi scara bermoral (etis) yang dimanifestasikan dalam tindakan konkrit melalui tingkah laku yang baik,jujur,bertanggung jawab,menghormati orang lain,toleransi, dan karakter lainnya.

Perilaku manusia lebih banyak berfungsi karena dibentuk oleh pengamatan dan dipengaruhi oleh proses meniru perilaku orang lain. Anak-anak melihat bagaimana orangtuanya perilaku tersebut. Untuk itu karakter perlu dibentuk dan dibina sejak usia dini. Pendidikan karakter sendiri memungkinkan kepada anak-anak adalah kunci utama membangun bangsa. Stiona Mangoenprosodjo dan Sri Nur Hidayanti menegaskan, bahwa orangtualah yang paling berperan dalam mengembangkan karakter anak. Peran sekolah hanyalah $20 \%$, kareana pembentukan karakter dimulai sejak anak masih keecil dan terus berproses hingga dewasa. ${ }^{4}$

Fakta yang tidak dapat dipungkiri bahwa karakter atau perilaku anak lebih banyak dipengaruhi oleh apa yang diamati anak yang ada di lingkungan sendiri atau orang terdekatnya. Biasanya perilaku itu dipelajari dengan meniruh apa yang diamati, sehingga semakin banyak contoh yang dilihat, semakin besar kemungkinan ditiru anak. Juga bahwa ada beberapa fakto

\footnotetext{
3 Sanderan, "Heuristika Dalam Pendidikan Karakter Manusia Toraja Tradisional."

4 “3 Jurnal PAK_ganjil 2016_2017_EXEMPLARY," n.d.
} 
penting perhatian pada pendidikan karakter, diantaranya adalah semakin kuatnya pengaruh di sekitar lingkuan atau dari orang terdekatnya juga media sebagai bentuk nilai-nilai para orang muda. Dan persepsi public tentang merosotnya karakter masyarakat, termasuk kecenderungan orang-orang muda untuk melakukan tindakan-tindakan kriminal, kekerasan, ketidaksopanan, kecurangan/menyontek, materialism, penggunaan obat-obat terlarang dan aktifitas seksual di luar nikah. Dengan demikian, perkembangan teknologi komunikasi saat ini merupakan tantangan yang tidak boleh dianggap remeh sebab hal itu bias berdampak buruk dan merusak masa depan generasi muda kita. Oleh sebab itu, peran orang tua dalam memberikan pendidikan karakter bagi generasi muda sangat penting untuk memprsiapkan masa depan mereka dengan lebih baik.

Pendidikan krakter yang baik menjidikan manusia memiliki akal yang selanjutnya mempukan ia berpikir lebih panjang dalam membuat atau memutuskan saat mengamati di sekitar lingkuannya dan pada orang terdekatnya. Pendidikan karakter di masa dini memudahkan untuk menilai saat bertindak dan menilai seseorang 


\section{Kesimpulan}

Pendidikan karakter adalah watak atau perilaku yang di implementasikan berlandaskan pada nilai yang telah tertanam sedangkan pengertian pendidikan karakter yaitu pendidikan kararkter adalah usaha menciptakan proses pembelajaran agar karakter seseorang aktid dalam menanamkan kebajikan pada karakter anak dalam cara bersikap. Tujuan dari pendidikan karakter adalah pembentukan karakter yang sesuai dengan landasan dasar Pancasila yang terkandung pada UUD 1945. Karakter yang dibentuk yaitu; taat pada keyakinan agama masingmasing, memiliki jiwa nasionalis dan patriotis, miliki sikap juju, toleran, kreatif, bertanggung jawab, dan adaptif terhadapa perubahan sosial dan budaya. Memiliki wawasan yang luas dan memiliki jiwa yang peka terhadap lingkungan sekitar.

Pendidikan karakter yang telah saya jelaskan ma' pasilaga tedong (adu kebrbau) dan ma' saung manuk (sabung ayam) bahwa pendidikan karakter sangat di maksimalkan peran penting pada orang tua.

\section{Saran}

Lebih menegaskan suatu pembentukan karakter dan bernalar secara spesifik bahwasannya pembentukan karakter masyarakat toraja sangat merosot dalam ruang lingkup pendidikan dan perlu melihat pola pemikiran masyarakat toraja masih sangat primitif saat melihat suatu problemtika masa kini. Lebih menghidupkan penerapan supralogika untuk membantu kemajuan masyarakat toraja, demikian penerapan ini terus diterapkan dalam ruang lingkup pendidikan masyarakat toraja perlahan merasakan suatu inovasi atau pemikiran baru. 


\section{DAFTAR PUSTAKA}

Rannu Sanderan. "Pendalaman Gagasan Hans-George Gadamer Tentang Intuisi Sebagai Supralogika." jurnal Ilmiah Relogiosity Ettiy Humanity(JIREH) VOL.2 (2020).

Sanderan, Rannu. "Heuristika Dalam Pendidikan Karakter Manusia Toraja Tradisional." BIA': Jurnal Teologi dan Pendidikan Kristen Kontekstual 3, no. 2 (2020): 306-327. “3 Jurnal PAK_ganjil 2016_2017_EXEMPLARY,” n.d. 